\author{
H. M. Oudemans-van Straaten \\ P. W. Elbers
}

\section{How to explain and exploit the beneficial effects of high-volume hemofiltration on hemodynamics and strong ion gap}

Received: 23 December 2012

Accepted: 6 January 2013

Published online: 30 January 2013

(C) Springer-Verlag Berlin Heidelberg and ESICM 2013

This editorial refers to the article available at: doi:10.1007/s00134-012-2800-0.

H. M. Oudemans-van Straaten $(\bowtie) \cdot$ P. W. Elbers

Department of Intensive Care, Vrije Universiteit Medical Center, De Boelelaan 1105, 1081 HV Amsterdam, The Netherlands

e-mail: hmoudemans@gmail.com

Tel.: +31-6-40496452

Fax: +31-20-4443901

Early high-volume hemofiltration has been suggested as adjuvant treatment for critically ill patients with severe septic shock to stabilize the circulation [1]. Several nonrandomized clinical and animal studies have shown a benefit [2]. The rationale for this treatment is that within the setting of an overwhelming inflammatory response, pro- and antiinflammatory mediators can be removed [3] and homeostasis restored [4]. Grootendorst et al. [5] had already found that substance removal by hemofiltration likely plays a role, because the infusion of ultrafiltrate from endotoxemic pigs depresses myocardial performance in normal pigs, while the infusion of ultrafiltrate from healthy pigs does not. However, a recent meta-analysis including randomized controlled trials and subgroups from randomized controlled trials was not able to show any benefit of continuous renal replacement therapy (CRRT) versus no CRRT or a higher dose of CRRT in patients with severe sepsis or septic shock in terms of survival, hemodynamics, pulmonary gas exchange, organ failure and length of stay [6]. The effect of CRRT on survival was not modified by CRRT dose. This was recently confirmed by a large randomized controlled trial [7].
Bellomo et al. [8] now specifically report on data from this trial from a nested cohort of 115 patients from two of the participating ICUs. Patients were treated with venovenous hemodiafiltration of either low intensity (with effluent flow at $25 \mathrm{ml} / \mathrm{kg} / \mathrm{h}$ ) or high intensity (at $40 \mathrm{ml} / \mathrm{kg} /$ $\mathrm{h})$. They focused on the control of metabolic acidosis, mean arterial blood pressure and noradrenaline dose and their relationship during the first $24 \mathrm{~h}$ of treatment. They found that $\mathrm{pH}$ and traditional markers of the metabolic component of acid base balance, i.e. bicarbonate and base excess similarly improved in both groups. However, in the high-intensity arm, lactate and in particular the strong ion gap (SIG) decreased significantly, concomitantly with an increase in mean arterial blood pressure and a decreased noradrenaline dose. These improvements were not observed in the low-intensity arm.

These results may be of clinical importance. But how do we explain and more importantly how do we exploit them?

\section{Substance removal and reversal of hypotension}

High-intensity CRRT likely removes more inflammatory mediators than the low-intensity modality. However, the removal of cytokines is often not sufficient to decrease plasma concentrations [9]. The reasons may be the high size and low free fraction of the cytokines, and the higher rate of production compared to removal. In contrast, freecirculating mediators in the middle molecular range, such as complement factors [1], prostaglandins and leukotrienes [10], and myocardial depressant factors [11] are removed [12, 13].

In the present study, SIG significantly decreased in the high-intensity group, which was not the case in the lowintensity group. This may indicate that substance removal contributed to improved hemodynamics. In this setting, SIG likely represents unmeasured strong anions. They 
accumulate in sepsis, renal failure and organ dysfunction, but their origin and chemical nature is only partially understood $[14,15]$. Increased glycolysis, protein catabolism, mitochondrial dysfunction and decreased clearance likely contribute to their accumulation. Potential candidates include sulfate, urate, hydroxybutyrate, succinate, pyroglutamate, D-lactate and Krebs cycle intermediates, but also components of drugs, nutrients or synthetic colloids [15-18]. However, despite using elaborate techniques to determine the components of SIG, the majority of its determinants are not yet identified [15].

The decrease in SIG paralleled the decrease in L-lactate [8]. Lactate removal by CRRT corresponds to lactate concentration in plasma times milliliters filtrate per minute, and is only a fraction of lactate production, being about $14 \mathrm{mmol} / \mathrm{kg} / \mathrm{min}$ [19]. Thus, the decrease in lactate more likely reflects improved circulation.

The decrease in SIG was much more pronounced in the high-intensity group. As we do not know normal levels of SIG 'production' in health and disease, we can only speculate on whether this decrease was caused by improved circulation or alternatively if it was contributing to improved hemodynamics, or at least its surrogate measurement mean arterial pressure. If so, this would be a possible therapeutic target. If not, the removal of 'something else' may have contributed to the improved homeostasis $[13,20]$.

\section{Cooling and reversal of hypotension}

This 'something else' could theoretically be heat. The authors mention that in all cases fluids were warmed to $37{ }^{\circ} \mathrm{C}$ or more. However, warming to $39^{\circ} \mathrm{C}$ is required to prevent the loss of heat in high-intensity CRRT. Thus if levels of warming were similar in the low- and highintensity modalities, heat loss would likely have been higher in the high-intensity arm. On the other hand, fever is ultimately mediated by prostaglandin E2 $\left(\mathrm{PGE}_{2}\right)$, a 352-kDa protein which freely passes the filter membrane [10]. Interestingly, $\mathrm{PGE}_{2}$ is not only the final mediator of fever but also causes hypotension. $\mathrm{PGE}_{2}$ is a direct vasodilator and inhibits the release of noradrenaline from the nerve endings. Thus, a higher rate of removal of $\mathrm{PGE}_{2}$ may have contributed to both cooling and a higher blood pressure in the high-intensity arm.

\section{Survival}

Although high-intensity CRRT induced an earlier stabilization of the circulation, it was not associated with improved survival. This seems a controversial finding because early goal-directed treatment of the circulation can improve patient outcome [21]. Furthermore, early lactate clearance is significantly associated with decreased levels of biomarkers, improvement in organ dysfunction and outcome in severe sepsis and septic shock [22]. We can only speculate why. In addition to its positive effects, high-intensity CRRT may have negative effects as well. First, high-intensity CRRT removes more beneficial substances, counteracting the beneficial removal of harmful compounds. Beneficial substances include micronutrients such as water-soluble vitamins, trace elements, amino acids and circulating beneficial mediators of whatever kind [23, 24]. In particular, hypophosphatemia may play a role as its incidence was increased by highintensity CRRT in the original trial from which the current nested cohort was taken [7]. A second issue deserving attention is that higher intensity CRRT requires a different antibiotic dosing schedule, and may therefore be associated with antibiotic under-dosing [25]. These possible harmful effects of high-intensity CRRT may explain why the favorable effects of early stabilization of the circulation do not translate into better survival.

\section{Conclusion}

High-intensity hemofiltration seems to contribute to early stabilization of the circulation in critically ill patients with acute kidney injury. This effect might be due to increased removal of components of SIG, other unknown mediators or loss of heat. However, this early beneficial effect does not translate into improved survival. This may be because we insufficiently compensate for its possible associated harm, such as increased loss of beneficial substances and inadequate antibiotic dosing. Avoiding harm of CRRT should be a clinical priority, but in selected patients, highvolume CRRT should not be overlooked.

\section{References}

1. Cole L, Bellomo R, Journois D, Davenport P, Baldwin I, Tipping P (2001) High-volume haemofiltration in human septic shock. Intensive Care Med 27:978-986
2. Bouman CS, Oudemans-van Straaten HM, Schultz MJ, Vroom MB (2007) Hemofiltration in sepsis and systemic inflammatory response syndrome: the role of dosing and timing. J Crit Care 22:1-12
3. Peng Z, Pai P, Hong-Bao L, Rong L, Han-Min W, Chen H (2010) The impacts of continuous veno-venous hemofiltration on plasma cytokines and monocyte human leukocyte antigen-DR expression in septic patients. Cytokine 50:186-191 
4. Ronco C, Tetta C, Mariano F, Wratten ML, Bonello M, Bordoni V et al (2003) Interpreting the mechanisms of continuous renal replacement therapy in sepsis: the peak concentration hypothesis. Artif Organs 27:792-801

5. Grootendorst AF, van Bommel EF, van Leengoed LA, van Zanten AR, Huipen HJ, Groeneveld AB (1993) Infusion of ultrafiltrate from endotoxemic pigs depresses myocardial performance in normal pigs. J Crit Care 8:161-169

6. Latour-Perez J, Palencia-Herrejon E, Gomez-Tellot V, Baeza-Roman A, Garcia-Garcia MA, Sanchez-Artola B (2011) Intensity of continuous renal replacement therapies in patients with severe sepsis and septic shock: a systematic review and meta-analysis. Anaesth Intensive Care 39:373-383

7. Bellomo R, Cass A, Cole L, Finfer S, Gallagher M, Lo S et al (2009) Intensity of continuous renal-replacement therapy in critically ill patients. N Engl J Med 361:1627-1638

8. Bellomo R, Lipcsey M, Calzavacca P, Haase M, Haase-Fielitz A, Licari E et al (2013) Early acid-base and blood pressure effects of continuous renal replacement therapy intensity in patients with metabolic acidosis. Intensive Care Med. doi: 10.1007/s00134-012-2800-0

9. Rimmele T, Kellum JA (2012) Highvolume hemofiltration in the intensive care unit: a blood purification therapy. Anesthesiology 116:1377-1387

10. Yokoyama K, Takabayashi S, Komada $\mathrm{T}$, Onoda $\mathrm{K}$, Mitani $\mathrm{Y}$, Iwata $\mathrm{H}$ et al (2009) Removal of prostaglandin E2 and increased intraoperative blood pressure during modified ultrafiltration in pediatric cardiac surgery. $\mathrm{J}$ Thorac Cardiovasc Surg 137:730-735
11. Blake P, Hasegawa Y, Khosla MC, Fouad-Tarazi F, Sakura N, Paganini EP (1996) Isolation of "myocardial depressant factor(s)" from the ultrafiltrate of heart failure patients with acute renal failure. ASAIO J 42:M911M915

12. Vanholder R, De SR, Glorieux G, Argiles A, Baurmeister U, Brunet P et al (2003) Review on uremic toxins: classification, concentration, and interindividual variability. Kidney Int 63:1934-1943

13. Neirynck N, Vanholder R, Schepers E, Eloot S, Pletinck A, Glorieux G (2012) An update on uremic toxins. Int Urol Nephrol. doi:10.1007/s11255-012-0258-1

14. Kellum JA, Kramer DJ, Pinsky MR (1995) Strong ion gap: a methodology for exploring unexplained anions. J Crit Care 10:51-55

15. Moviat M, Terpstra AM, Ruitenbeek W, Kluijtmans LA, Pickkers P, van der Hoeven JG (2008) Contribution of various metabolites to the "unmeasured" anions in critically ill patients with metabolic acidosis. Crit Care Med 36:752-758

16. Forni LG, McKinnon W, Hilton PJ (2006) Unmeasured anions in metabolic acidosis: unravelling the mystery. Crit Care 10:220

17. Guth HJ, Zschiesche M, Panzig E, Rudolph PE, Jager B, Kraatz G (1999) Which organic acids does hemofiltrate contain in the presence of acute renal failure? Int J Artif Organs 22:805-810

18. Rocktaeschel J, Morimatsu H, Uchino S, Bellomo R (2003) Unmeasured anions in critically ill patients: can they predict mortality? Crit Care Med 31:2131-2136
19. Bollmann MD, Revelly JP, Tappy L, Berger MM, Schaller MD, Cayeux MC et al (2004) Effect of bicarbonate and lactate buffer on glucose and lactate metabolism during hemodiafiltration in patients with multiple organ failure. Intensive Care Med 30:1103-1110

20. Mutsaers HA, Wilmer MJ, Reijnders D, Jansen J, van den Broek PH, Forkink M et al (2013) Uremic toxins inhibit renal metabolic capacity through interference with glucuronidation and mitochondrial respiration. Biochim Biophys Acta 1832:142-150

21. Rivers E, Nguyen B, Havstad S, Ressler J, Muzzin A, Knoblich B et al (2001) Early goal-directed therapy in the treatment of severe sepsis and septic shock. N Engl J Med 345:1368-1377

22. Nguyen HB, Loomba M, Yang JJ, Jacobsen G, Shah K, Otero RM et al (2010) Early lactate clearance is associated with biomarkers of inflammation, coagulation, apoptosis, organ dysfunction and mortality in severe sepsis and septic shock. J Inflamm (Lond) 7:6

23. Story DA, Ronco C, Bellomo R (1999) Trace element and vitamin concentrations and losses in critically ill patients treated with continuous venovenous hemofiltration. Crit Care Med 27:220-223

24. Berger MM, Shenkin A, Revelly JP, Roberts E, Cayeux MC, Baines $M$ et al (2004) Copper, selenium, zinc, and thiamine balances during continuous venovenous hemodiafiltration in critically ill patients. Am J Clin Nutr 80:410-416

25. Bouman CS (2008) Antimicrobial dosing strategies in critically ill patients with acute kidney injury and high-dose continuous veno-venous hemofiltration. Curr Opin Crit Care 14:654-659 